\title{
FORMAÇÃO DO LEITOR: USO DE TEXTOS DIVERSOS E APLICAÇÃO DE ESTRATÉGIAS DE LEITURA
}

\author{
Magali de Moraes Menti ${ }^{1}$, Dayse Cristina Ferreira da Silva ${ }^{2}$
}

\begin{abstract}
${ }^{1}$ Universidade Estadual do Rio Grande do Sul - UERGS, Rua Bento Gonçalves, 8855, Agronomia, CEP: 91540-000, Porto Alegre, RS, Brasil. Fone: 51 32281731. E-mail: magali-menti@ uergs.edu.br. ${ }^{2}$ Faculdade Senac Porto Alegre - FSPOA, Rua Coronel Genuíno, Centro Histórico, CEP: 90010-350, Porto Alegre, Rs, Brasil. Fone: 51 30221044. E-mail: dcfdasilva@gmail.com
\end{abstract}

Resumo - O presente trabalho tem como motivação mostrar a importância e a contribuição da leitura no seu contexto social, utilizando-se de uma pesquisa bibliográfica de livros e artigos que trazem como tema as estratégias de leitura. A preocupação com o espaço que a leitura tem e a forma como ela é trabalhada, principalmente em sala de aula, tem sido motivação para diferentes pesquisadores interessados em aplicar estratégias que desenvolvam a capacidade de compreensão na prática leitora. Essa prática se mostra imprescindível na vida escolar e social de cada pessoa à medida que ler favorece o senso crítico, o poder de escolha e a habilidade de opinar. Para que um leitor apresente tais características, as estratégias de leitura vêm sendo utilizadas e defendidas por teóricos e especialistas da área. As estratégias são procedimentos que ajudam um leitor a se tornar autônomo se orientado e acompanhado adequadamente. Elas ajudam o leitor a construir o sentido do seu texto, fazendo-o processar a leitura, antecipando conhecimentos e hipóteses a respeito da sua leitura. Com as estratégias de leitura, espera-se que o leitor entenda o sentido e o significado do que leia. É fundamental também seguir algumas normas em relação ao trabalho a ser realizado com a leitura. Um dos cuidados é quanto à escolha do gênero textual que interfere no sucesso da atividade proposta.

Palavras-chave: Estratégia de leitura. Leitura. Leitor. Gêneros textuais.

Abstract - The present article aims at showing the importance and the contribution of reading in its social context, using a literature review and articles on reading strategies. The concern with the importance of reading and how it is worked, especially in the classroom, has been the motivation for researchers interested in applying strategies that develop the ability to understand the reading practice. This practice proves indispensable in school and social life as reading favors critical thinking, the power of choice and the ability to speak one's mind. For a reader to present such characteristics, the use of reading strategies have been defended by theorists and scholars. The strategies are procedures that help a reader to become autonomous while being guided and properly monitored. They help readers build the meaning of their text, anticipating knowledge and assumptions about the reading. With reading strategies, it is expected that the reader understand the meaning of what they read. It is also important to follow some rules regarding the work to be done with reading. The choice of genre influences the success of the proposed activity.

Keywords: Reading strategies. Reading. Reader. Genre.

Recebido em: 25 de novembro de 2015 Aprovado em: 29 de dezembro de 2015

\section{INTRODUÇÃO}

A dificuldade em ler, e ler bem, é uma situação já enfrentada por brasileiros de todas as idades. Uma tentativa para estimular a leitura, incentivando o hábito de ler, é uma ação que pode ser aplicada à leitura de textos diversos para desenvolver cidadãos pensadores e críticos. Para a elaboração deste trabalho, levantou-se a preocupação de como ensinar a ler. A escolha do tema se justifica pela preocupação em se ressignificar a importância da leitura, seu hábito, seu gosto, desenvolvendo estratégias de leitura que possibilitem ensinar a ensinar, ensinar a ler e ensinar a aprender. Se jovens e adultos apresentam dificuldade de interpretação porque não têm o hábito da leitura, tentar-se-á responder como o ensino ou desenvolvimento de estratégias de leitura contribuem para a formação do leitor.

Ler não significa decodificar os códigos linguísticos, mas vai além. Existe, segundo Koch e Elias (2012, p. 12), a interação autor-texto-leitor, sendo o autor aquele que transmite algo, o texto que é o produto contendo as ideias do autor e o leitor o grande responsável por permitir que aquele texto seja 
um texto, atribuindo a sua leitura, seu sentido, suas experiências.

As estratégias de leitura são técnicas usadas pelo leitor permitindo que ele chegue à compreensão dessa leitura. Essas estratégias de leitura devem ser aplicadas considerando as diferentes tipologias textuais e seus gêneros, sendo o texto o produto que fará o leitor decodificar seu código, dando-lhe sentido através das informações explicitamente expostas, mas constituindo também informações implicitamente sugeridas por esse leitor (KOCH; ELIAS, 2012).

Sendo o gênero literário a organização que se faz para classificar diferentes textos conforme sua espécie, classe e origem, há alguns teóricos que consideram "o gênero como categoria imutável" e valorizam a obra obedecendo suas leis fixas de estruturação. Outros teóricos, por causa da criação artística, dizem que em uma obra há uma mistura de gêneros, já que cada obra pode apresentar combinações diversas quanto às características textuais (SOARES, 2007).Não se pode, por exemplo, considerar apenas os livros de literatura como fonte de leitura única, sabendo-se que há muitas manifestações que permitem leituras significativas (BORDINI; AGUIAR, 1988).

O que é ler? O que é leitura? O que é letramento? O que é literatura? O que é gênero textual? O que é estratégia de leitura? São os questionamentos que nortearão esta pesquisa, buscando corroborar com a hipótese de que o indivíduo tem necessidade de dar sentido ao que faz e ao ambiente em que vive, o mundo, e o livro é o instrumento que o leva a dialogar com esse mundo.

Deve-se também considerar livros de literatura como fonte de assuntos tecnicamente pedagógicos que podem conduzir à área do conhecimento de quem lê, levando-os a fazer comparações, inferências, indagações etc. Desta forma, incentivar a leitura e identificar elementos que interferem na formação do aluno leitor, por exemplo, pode ser a constatação de que a leitura do prazer é a base para a formação do leitor. Além disso, definir conceitos que envolvam o hábito da leitura, analisar aspectos que envolvam estratégias de aprendizagem e de leitura e despertar o interesse pelo hábito da leitura são também os objetivos aqui apresentados.

A primeira parte do artigo apresentará conceitos e definições sobre o que é ler, o que é leitura, o que é letramento, o que é literatura, o que é gênero textual e o que são estratégias de leitura. Essa teorização parece ainda estar latente diante de tantos estudos já realizados. Procurar-se-á, na segunda parte do artigo, responder a essas indagações a partir de uma pesquisa bibliográfica. Essa pesquisa bibliográfica é referente aos artigos: Dicas de estratégias de leitura de Carla Viana Coscarelli (FALE/UFMG), Estratégias de leitura de Isabel Solé, A formação do leitor competente: estratégias de leitura de Maria de Jesus Ornelas Valle, Desenvolvimento da compreensão leitora: por um ensino estratégico e efetivo da leitura de Rosângela Maria Couto e Paulo Leandro de Carvalho (Faculdade Três Pontas/ MG) e Estratégias de leitura e gêneros textuais na formação do leitor crítico de Eliane de Fátima Manenti Rangel (UNIFRA).

\section{MATERIAIS E METODOLOGIA}

\subsection{Fundamentação Teórica}

Leitura é um assunto que se tornou estudo para muitos interessados e preocupados com a importância que essa comunicação verbal é capaz de provocar. De acordo com Alcure, Ferraz e Carneiro (1996, p. 44), "através da comunicação verbal, simbólica e abstrata, que se faz por palavras - faladas ou escritas - o homem pôde compreender e dominar o mundo que o rodeia." Entende-se por comunicação verbal a linguagem que o homem utiliza para se comunicar com os demais. Para falar de leitura, é necessário levantar alguns aspectos relevantes acerca dessa discussão. De acordo com Koch e Elias (2012, p.9), há questões que se destacam quando se levanta o fato da importância da leitura na vida de crianças, jovens e adultos. São perguntas que podem ser usadas para motivar o leitor a cultivar o hábito da leitura: o que é ler? Para que ler? Como ler? Quem são os responsáveis por esse incentivo? As autoras afirmam que essas perguntas podem ser respondidas de maneiras diferentes, porém, é preciso também discorrer sobre a "concepção da leitura, de sujeito, de língua, de texto e de sentido".

Ler é uma atividade que envolve interação entre o leitor e o texto (KOCH; ELIAS, 2012, p. 12). Essa interação acontece dependendo da habilidade demonstrada pelo leitor ao usar os elementos linguísticos que compõem esse texto, além da experiência de mundo que o leitor também tem. Obter informações sobre a obra, o autor e o assunto, faz com que quem leia construa sentidos que o levem a interpretar, questionar, opinar etc.

A leitura é uma prática que proporciona o envolvimento do leitor com o texto. Há, então, uma interação que acontece para satisfazer algo, ou seja, quem lê quer saber mais, conhecer mais, debater mais, entre outras coisas que a leitura pode proporcionar. Ler envolve aspectos que vão da compreensão do texto ao conhecimento de mundo e os do próprio texto (KOCH; ELIAS, 2012, p. 19). Logo, ler é uma prática que acontece com a própria prática da leitura.

Um leitor é capaz de criar estratégias de leitura que o levem à informação desejada, pois quem lê quer desfrutar da mensagem que está diante de si. As 
estratégias de leitura são técnicas ou procedimentos que o leitor utiliza para compreender sua leitura. Trata-se, segundo Koch e Elias (2012, p. 13), de uma "concepção de leitura, que põe em foco o leitor e seus conhecimentos em interação com o autor e o texto para a construção de sentido". Os leitores recorrem às estratégias para construir o sentido da leitura fazendo antecipações e criando hipóteses com base no conhecimento que têm sobre o autor, o título, o texto, o gênero textual etc. Conforme o avanço na leitura acontece, as antecipações feitas e as hipóteses criadas são confirmadas ou rejeitadas. As hipóteses podem ser formuladas tantas quantas o conhecimento do leitor permitir, pois como leitor ativo, a capacidade de criar novas hipóteses e reformulá-las acontece naturalmente porque cada leitor tem conhecimento prévio sobre a língua, experiências vividas, leituras de outros textos que é ativado no processo de interação que esse leitor tem com o texto.

A leitura ensina, motiva, encoraja e entretém ao mesmo tempo em que as inferências, relações e perguntas são feitas. Esses aspectos envolvendo a leitura caracterizam seu objetivo, o objetivo que o leitor tem ao ler algo, variando de acordo com a sua vontade. Saber ler é dominar um assunto, ou adquirir autonomia para debater, criticar, opinar. Entretanto, é possível ensinar a ler? Acredita-se que o incentivo à leitura é possível, e necessário, mas o aprender a ler é algo individual, pois segundo Lois (2010, p. 50), “a leitura se sobrepõe ao estudo porque o estudo é a formalização de um universo que vem sendo lido pela humanidade; a leitura é o que conduz o homem a pensar sobre".

A literatura proposta para a prática da leitura é determinante para que o leitor aceite ou recuse determinada leitura. Segundo Bordini e Aguiar (1988, p. 13) "todos os livros favorecem a descoberta de sentidos, mas são os literários que o fazem de modo mais abrangente." Isso acontece porque a imitação meche com a imaginação do leitor, além de a linguagem ali presente aproximar o leitor da sua condição humana. $\mathrm{O}$ que não se pode aceitar é o fato de a literatura ser entendida como um trabalho realizado com a utilização de livros literários apenas. A literatura trata de textos diversos desde a leitura de histórias em quadrinhos até a leitura de uma bula como afirma Koch e Elias (2012, p. 101).

Nesse contexto, a literatura abrange diferentes gêneros textuais que têm infinitas possibilidades de classificação, apresentando também muitas variações na sua constituição. As crônicas, os contos, os romances, são alguns exemplos de gêneros textuais. Há muito tempo o conceito literário de gênero textual, estanque a apenas alguns tipos de texto, não é mais aceito por muitos autores Marcuschi (2003, p.19) apud Rangel (2007, p.6). Isso porque a diversidade de textos é imensa, dificultando uma classificação precisa. Ao se estudar gêneros textuais é fundamental levar em conta a época. Com o advento da comunicação eletrônica, o e-mail, por exemplo, é um tipo de gênero textual que está diretamente relacionado à época atual. Segundo Staiger (apud Soares, 2007, p. 19), analisando os gêneros textuais, uma única obra não pode ser considerada apenas "lírica, ou épica ou dramática, não só por não apresentar apenas características de um único gênero, mas também porque essas características não se projetam, na constituição da linguagem, sempre da mesma maneira."

Outra questão que surpreende acerca da importância da leitura é a falta de interesse pela leitura, por parte dos estudantes principalmente, ser bastante significativa (LOIS, 2010, p. 16). Se a leitura é de vital importância, por que esses estudantes não se sentem seduzidos por esta prática?

Algumas justificativas para o não sucesso do incentivo à leitura referem-se à maneira como o desenvolvimento do ato de ler é conduzido nas escolas. No passado, o estudante leitor recebia as informações contidas no texto e as decorava. A ele não era dada a oportunidade de desenvolver seu senso crítico sobre a leitura realizada (LOIS, 2010, p.17). Neste aspecto, a alfabetização era o foco. O aluno alfabetizado era capaz de ler, de decodificar. Esse conceito de ser alfabetizado para ler os códigos linguísticos não serve mais, pois a leitura não se limita a isso, mas proporciona escolhas. É urgente, então, que se estabeleça a diferença entre alfabetização e letramento. A alfabetização está diretamente relacionada a saber ler e escrever (SOARES, 1999) apud (LOIS, 2010, p. 18), enquanto letramento está ligado à condição de escolher o que se quer ler, como sugere Lois (2010, p.19):

Ser letrado é estar vivo ao que a cultura tem a nos
oferecer. É não se contentar só com a leitura dos
livros. É poder ver além do escrito. É demarcar
seu território. Assumir a própria palavra e não
deixar que ela seja a reprodução da palavra do
outro.

Resumir o conceito de letramento ao conceito de alfabetização é preocupante, limitando a leitura ao simples processo de decodificação, repetição ou reprodução do que já existe. O iniciante leitor é o maior prejudicado. Embora seja apresentado ao mundo das letras, dele é tirado o incentivo da construção do seu pensamento crítico.

Estar atento à leitura, entender as partes significativas do texto e dar sentido ao que se lê são estratégias que podem ser desenvolvidas para uma boa prática leitora. Usar estratégias de leitura é fundamental porque se trabalha a leitura de diversas 
maneiras. Afirmar que essas estratégias são procedimentos infalíveis para que o desenvolvimento e a compreensão da leitura aconteçam de maneira natural não é uma verdade absoluta. Cada leitor se adaptará a uma estratégia de leitura, melhorando seu poder de compreensão. Esses procedimentos acontecem à medida que o leitor se pergunta qual o objetivo da leitura que irá realizar, como monitorar a leitura procurando o significado do que está lendo, como usar o dicionário para estabelecer significados que não foram possíveis de serem compreendidos dentro daquela contextualização, quando resumir para realmente entender o que está lendo, entre outras (COSCARELLI, [2012?]).

Não é exagero admitir que o tipo de material apresentado para leitura é outro fator a ser bem analisado. A escolha de livros deve ser cuidadosamente selecionada, e a explicação de diferentes tipos de livros também deve ser feita apesar de a defesa pelos livros de literatura e principalmente pelos clássicos universais serem sempre considerados como aqueles que proporcionam a descoberta dos sentidos de maneira mais abrangente, como é enfatizado por Machado (2002, p.75):

[...] de qualquer maneira, toda narrativa literária se constrói em cima de elementos que vão se correspondendo de modo coerente e que aos poucos vão erigindo um edifício de sentido. É para isso que o homem conta histórias - para tentar entender a vida, sua passagem pelo mundo, ver na existência uma espécie de lógica. Cada texto e cada autor lidam com elementos diferentes nessa busca, e vão adequando formas de expressão e conteúdo de um jeito que mantém uma coerência interna profunda que lhe dá sentido.

A busca por respostas de como a leitura deve ser trabalhada, principalmente nas escolas, é um tema bastante discutido no meio acadêmico. A nova modalidade de avaliação Exame Nacional de Ensino Médio (ENEM) exige a leitura, a análise e a compreensão de questões objetivas referentes a quatro áreas do conhecimento, considerando linguagens, códigos e suas tecnologias (incluindo redação); ciências humanas e suas tecnologias; ciências da natureza e suas tecnologias e matemáticas e suas tecnologias. Isso mostra a importância que a leitura tem na sociedade letrada, proporcionando sua plena participação social (COUTO; CARVALHO, [2007?]).

O descaso com a leitura apresentado pelos alunos pode ser justificado porque são forçados, na maioria das vezes, a procurarem respostas às perguntas direcionadas pelo professor. As perguntas de certas atividades pedem por respostas já prontas, não estimulando a curiosidade pela leitura. $\mathrm{O}$ aluno demonstra desinteresse em colocar em prática tal atividade, pois está trabalhando apenas os códigos, sem se aprofundar em uma leitura de interpretação de sentidos. Agindo dessa forma, o aluno inevitavelmente faz uma leitura superficial do texto, esperando apenas que alguém mostre a resposta tanto esperada. Ele não se esforça para entender o que está lendo, não mergulha no seu texto para fazer uma leitura prazerosa, mas para buscar algo que lhe foi conferido: encontrar respostas. $\mathrm{O}$ resultado são leituras mal feitas e esquecidas facilmente (COSCARELLI, [2012?]). Sendo a leitura um processo de interação entre o leitor e o texto, sua finalidade está diretamente relacionada com o objetivo que se tem ao se ler: fantasiar, devanear, imaginar, viajar etc. Dependendo do gênero textual, esse objetivo será alcançado ou não porque "os gêneros apresentam mudanças, em sintonia com o sistema da literatura, a conjuntura social e os valores da cada cultura" (SOARES, 2007, p. 18).

Quando o leitor está envolvido com a leitura de livros, ele consegue construir mais interpretações, pois o envolvimento com essa leitura faz com que quem leia crie hipóteses. Mas, isso acontece se o leitor for capaz de controlar a própria leitura como afirma Solé (2004, p. 1) e esse controle se dá com possíveis inferências. Esquemas, estratégias, dicas de leitura são formas que vêm sendo desenvolvidas para ensinar a ler. Solé $(2014$, p. 1) continua afirmando que infelizmente se tem notícia de que há pessoas que não gostam, ou não querem ler. $\mathrm{O}$ número de pessoas é ainda maior nas escolas, entre os alunos. Por um lado, a deficiência ao incentivo à leitura, de outro, alunos que não fazem esforço para realizar uma leitura autônoma. Não é objetivo deste trabalho se aprofundar no letramento das crianças, mas é importante dizer que o aprendizado da escrita e da leitura é essencial para que ao final desse processo se tenha leitores capazes de utilizar os recursos da leitura para desenvolvê-la de maneira eficiente, pois o "controle da compreensão é um requisito essencial para se ler de forma eficaz.", segundo Solé (2014, p.2).

Logo, a leitura deve ser significativa, motivadora e interessante para quem lê. Como trabalhar essa motivação nas escolas? Como o professor pode envolver os alunos no processo da leitura? Sabe-se que se trata de uma atividade desafiadora: trabalhar leitura na sala de aula. Há uma diversidade muito grande de alunos e interesses, mas cabe ao professor propiciar esse interesse, buscando suportes que incentivem a leitura, a começar pela escolha e análise do conteúdo. Outro aspecto importante é o de não limitar essa prática a tarefas que perguntem nomes de personagens, características 
dos lugares, etc. De acordo com Solé (2014, p. 2), fazer esse tipo de atividade é focar no interesse da decodificação, ou seja, trabalhar apenas os códigos da escrita, sem se importar com o que a leitura tem de mais importante: descobrir o novo. "A leitura nos aproxima da cultura, por isso, um dos objetivos da leitura é ler para aprender." como diz Isabel Solé (2014), ou seja, deve-se ensinar a ler porque a leitura cria um instrumento de aprendizagem: aprende-se a aprender. A leitura também satisfaz à medida que informa, que responde a curiosidades, que motiva. Esse aprender pode começar com leitura feita pela família. A existência de um ambiente onde a promoção da leitura aconteça antes de ela ir para a escola tem influência decisiva no desenvolvimento desse jovem leitor. Ele se familiariza com as palavras, aumentando seu interesse na escola, pois lá descobre que pode fazer mais. O que não pode, ou não poderia acontecer, é a falta de interesse na leitura estar relacionada à expectativa que se tem em relação a ela justamente na escola.

Sabendo que a alfabetização é a iniciação do letramento, é nesse momento que o trabalho da escrita e da leitura deve ser destacado. O ensino da leitura e o seu significado deve ganhar força para que o aluno perceba que "aprender a ler significa aprender a encontrar sentido e interesse pela leitura" (SOLE, [2000?]). Apresentar diferentes tipos de textos e explicá-los é o que alguns autores defendem para criar expectativas. Trabalhar os textos narrativos, descritivos, informativos, expositivos, entre outros, é organizar, de certa forma, a leitura, mostrando para o leitor que ele consegue compreender melhor sua leitura com algumas pistas. Essas pistas também levam o leitor a entender os objetivos que eles têm com a leitura, pois se lê para aprender, para seguir instruções, para obter informações, por prazer.

Ao conhecemos nossas dificuldades, tais como compreensão do vocabulário, por exemplo, podemos seguir algumas estratégias de leitura para conseguir estabelecer uma relação entre o texto e o que já possuímos de conhecimento, encontrando assim o objetivo da nossa leitura. Seja qual for o objetivo de um leitor, esse objetivo determinará a maneira como lê. "A eficiência de sua leitura será diretamente proporcional ao esforço e à habilidade que imprimir na tarefa" (ADLER; DOREN, 1972, p. 37).

As estratégias de leituras devem ser usadas pelo leitor, pois é um exercício, uma prática que garante a compreensão do que se quer entender porque quem lê descobre. Essa descoberta é enfatizada, de certa forma, ao longo deste trabalho. Estimular a ler é possível, e isso começa desde cedo. A escola deveria ser o lugar onde se descobre que ler mais e melhor é algo que cada leitor pode adquirir, sendo orientado e seguindo algumas estratégias que o ajudem a assimilar o texto. Dominar essas estratégias é o que acontece com o leitor autônomo, que se torna competente na prática leitora.

Adler e Doren (1972) apresentam níveis de leitura, referindo-se à Leitura Elementar, Leitura Inspecional, Leitura Analítica e Leitura Sintópica. O nível elementar refere-se a alfabetização, à leitura básica; o nível inspecional refere-se se à capacidade que o leitor tem de em pouco tempo, com uma leitura rápida, saber sobre o quê o livro trata; o nível analítico refere-se à dedicação que o leitor dispõe em relação à leitura para dela extrair o máximo de aproveitamento; o nível sintópico refere-se à comparação que o leitor consegue fazer com outras leituras já realizadas. Nem todos os leitores atravessam todos esses níveis, mas todos que leem chegam a pelo menos aos níveis de leitura elementar e/ou inspecional. A importância de se desenvolver estratégias de compreensão de leitura ao se ensinar estratégias de compreensão está relacionada a esses níveis de leitura.

\subsection{Metodologia}

A pesquisa aqui relatada é bibliográfica. Tratase de uma pesquisa desenvolvida com base em material já elaborado. No presente trabalho foram usados como referências livros e artigos científicos que tratam do tema relacionado a estratégias de leitura e tudo o que o ato de ler envolve: ensinar, aprender e estimular o hábito da leitura. Sabe-se que os livros constituem as fontes bibliográficas por excelência (GIL, 2002, p. 44), e são classificados como leitura corrente ou de referência. Foram usados livros de referência remissiva.

Este trabalho foi exclusivamente desenvolvido a partir de fontes bibliográficas com a escolha de livros sobre leitura, estratégias de leitura e gêneros textuais usados na fundamentação teórica. Os autores escolhidos, Bordini e Aguiar (1988), Koch e Elias (2012), Lois (2010) e Soares (2007), sustentaram a teoria sobre leitura, suas estratégias e seus estímulos.

Após a escolha da bibliografia apresentada na fundamentação teórica, pesquisou-se na internet artigos científicos, acessados em 19 de outubro de 2014, usando-se as seguintes palavras: estratégias de leitura, estratégias de leitura Isabel Solé, estratégias de leitura Isabel Solé download e estratégias de leitura e gêneros textuais. Foram encontrados centenas de artigos, e pelo desenvolvimento e foco do assunto, foram selecionados os artigos sobre Dicas de estratégias de leitura de Carla Viana Coscarelli (FALE/UFMG), Estratégias de leitura de Isabel Solé, A formação do leitor competente: estratégias de leitura de Maria de Jesus Ornelas Valle, Desenvolvimento da compreensão leitora: por um 
ensino estratégico e efetivo da leitura de Rosângela Maria Couto e Paulo Leandro de Carvalho (Faculdade Três Pontas/ MG) e Estratégias de leitura e gêneros textuais na formação do leitor crítico de Eliane de Fátima Manenti Rangel (UNIFRA).

Resumiu-se, então, os artigos selecionados, e uma comparação sobre a análise desses artigos com o exposto na fundamentação teórica foi feita para tentar responder a pergunta como ensinar a ler e estimular a leitura para desenvolver leitores, utilizando estratégias de leitura?

\section{RESULTADOS E DISCUSSÃO \\ 3.1 Resumo dos artigos}

No artigo Dicas sobre estratégias de leitura de Carla Viana Coscarelli ([2012?]) (FALE/UFMG), a autora afirma que a dificuldade que muitos alunos têm ao demonstrar sua capacidade de compreensão sobre qualquer leitura é fato, e a busca por respostas de como a leitura deve ser, então, trabalhada, principalmente nas escolas, é um tema que merece especial atenção.

Tratando-se do exposto, há no artigo três razões pelas quais alunos, supostos leitores, fazem o que se considera uma pseudoleitura, pois estão 1 procurando respostas; 2 - processando a leitura superficialmente e 3 - lendo e esquecendo. Então, algumas causas para o descaso com a leitura apresentadas pelos alunos é porque eles procuram respostas já prontas em textos que o professor lhes proporciona. Nesse tipo de leitura, o aluno só tem que responder à questão que o professor perguntou. Agindo dessa forma, o aluno inevitavelmente faz uma leitura superficial do texto, esperando que alguém mostre a resposta tanto esperada. Ele não se esforça para entender o que está lendo, não mergulha no seu texto para fazer uma leitura prazerosa, mas para buscar algo que lhe foi conferido: encontrar respostas. O resultado são leituras desinteressantes.

No artigo, há a ênfase de que uma leitura que permite estratégias proporciona um melhor entendimento, ou seja, quando se lê com atenção, com concentração, desenvolvendo algumas estratégias de leitura, isso ajuda leitores a serem leitores, logo, "relacionar conhecimentos, tecer significados, monitorar a leitura e criar sentidos" são algumas estratégias que podem ser desenvolvidas para uma boa leitura.

Há também uma preocupação em mostrar que essas estratégias não são dicas infalíveis para que o desenvolvimento e a compreensão da leitura aconteçam de maneira natural. Cada leitor se adaptará a uma estratégia de leitura, melhorando seu poder de compreensão. No artigo Estratégias de leitura de Isabel Solé, a autora desenvolve seu estudo sobre o desafio e o ensino da leitura para ler, compreender e aprender e o ensino de estratégias de compreensão leitora para compreender antes, durante e depois da leitura. São oito os capítulos apresentados por Solé acerca das estratégias leitoras.

A definição de leitura, segundo a Isabel Solé (2014), é o processo de interação que há entre o texto e o leitor. A autora enfatiza ainda que quando se lê se tem um propósito e esse propósito varia conforme a necessidade de cada leitor. O leitor tem interesse em determinado texto e o compreende porque carrega consigo conhecimento compartilhados com o conhecimento do texto também. Entende-se, então, que há um controle na leitura realizada, ou seja, estratégias usadas por quem lê para compreender melhor o texto. Infelizmente a leitura na escola apresenta outro foco: ler corretamente apenas, e sua prática não tem se mostrado tão eficiente em um ambiente onde o hábito pela leitura deveria ser desenvolvido constantemente.

Quando Solé (2014) fala de ler, compreender e aprender, a autora mostra a importância de se adquirir estratégias de leitura para se ter controle do objeto de leitura. A compreensão só é possível quando se tem controle do que se está lendo. A leitura significativa e motivadora favorece a compreensão que acontece naturalmente. $\mathrm{Na}$ escola, deve-se estimular isso, mesmo com a diversidade encontrada nas salas de aula. O professor é responsável por selecionar minuciosamente o conteúdo a ser explorado pelos alunos. Agindo assim, o professor estará proporcionando uma aprendizagem significativa, aproximando-os da cultura. Ler é se aproximar da cultura com o objetivo de aprender sempre mais, e aprender mais significa também dispor de estratégias que assegurem a compreensão da leitura.

Solé (2014) também afirma que a leitura estimulada desde cedo pela família, especialmente pelos pais, influencia o desenvolvimento da leitura na vida dos futuros alunos leitores. Fazer a criança perceber que ler é divertido, e que elas podem dominar este universo de palavras, pode instigá-las, aumentando seu interesse por um mundo cheio de significados. A escola tem papel determinante, promovendo atividades que despertem ainda mais o interesse da criança pela leitura. A escrita e a leitura, por exemplo, devem ser trabalhadas como procedimentos em sala de aula. É preciso reforçar que o professor é responsável por orientar os alunos nesta primeira etapa, para que depois ocorra a prática individual, ou seja, o aluno se tornar independente, desenvolvendo as habilidades de leitura. Saber classificar os textos em narrativo, descritivo, expositivo e instrutivo-indutivo também é enfatizado por Solé. 
Para compreender antes da leitura, Solé (2014) apresenta passos para que a compreensão de determinada leitura aconteça antes mesmo que ela seja feita. A motivação deve ser o ponto de partida para que a leitura seja significativa. Em construindo a compreensão durante a leitura, a utilização de um resumo é o que Solé destaca para a reprodução do que é essencial no texto e o que é secundário. $\mathrm{O}$ professor deve ser o orientador, mostrando como as estratégias de leitura funcionam, tornando os alunos competentes leitores ao conseguir controlar a leitura realizada. Para depois da leitura, continuar compreendendo e aprendendo, a ideia das estratégias, do resumo e a importância de se identificar a ideia principal do texto são reforços nos quais o leitor deve persistir. E o papel do professor é orientar o aluno passo a passo na realização da leitura: o que estão lendo, por que, qual a ideia principal etc. A importância do resumo ganha destaque porque ao resumir o leitor utiliza suas próprias palavras para entender o que está lendo.

O artigo A formação do leitor competente: estratégias de leitura de Maria de Jesus Ornelas Valle ([2007?]) apresenta uma pesquisa realizada a partir de estudos sobre estratégias de leitura segundo os pressupostos teóricos de Isabel Solé. Valle ([2007?]) aplica procedimentos para a construção de bases necessárias para a formação de leitores em uma pesquisa realizada no ensino fundamental. Para ela, usar as estratégias de leitura requer que esta seja significativa. O professor é o responsável por promover o acesso à leitura orientando passo a passo como aprender estratégias que favoreçam a compreensão leitora. Ela afirma que os alunos precisam assistir a um processo de leitura, mostrada pelo professor, para que lhes sejam possibilitadas as estratégias que favorecerão a compreensão do texto.

Apenas aqueles que têm acesso ao letramento são capazes de usufruir do conhecimento adquirido e continuam aprendendo e se desenvolvendo com novas experiências de leitura. Segundo Valle ([2007?]), a escola é responsável por esse letramento e pela formação de leitores que gostem de ler. O aluno que diz que não gosta de ler, não entende o que lê ou não consegue identificar informações relevantes na leitura que realiza não possui o letramento, fundamental para o exercício de sua cidadania e o enfrentamento de desafios diários.

A apresentação de um texto sugere múltiplas interpretações, e é o professor o mediador capaz de direcionar a atividade possibilitando ao aluno um elo com o texto. É enfatizado neste artigo que ler é compartilhar de saberes exteriores, conhecimentos que o leitor carrega consigo, e de entendimentos proporcionados pela própria leitura. Essa interação acontece à medida que a leitura é aprofundada pela decodificação da língua, pela compreensão do tema e das ideias principais, pela interpretação que se é capaz de fazer da leitura e pela retenção da informação, absorvida pela compreensão e interpretação. Para a realização de sua pesquisa, com a aplicação da prática de leitura em sala de aula, Valle ([2007?]) considera as três etapas de leitura de Solé (1998). Ao desenvolver uma atividade com o texto deve-se aplicar o antes, o durante e o depois da leitura, ou seja, informações sobre o texto, a obra, o autor e a antecipação do tema e do conhecimento prévio desse tema constituem o antes da leitura. Durante a leitura, trabalhar com o significado das palavras, com as expectativas criadas ao se deparar com o texto, com a identificação do tema principal, direciona a leitura para uma confirmação ou rejeição do que se lê. Depois da leitura, a troca de informações, a avaliação dessas informações, as opiniões referentes ao texto e a crítica fecham o ciclo da utilização das estratégias de leitura que auxiliam a alcançar total domínio na prática leitora.

Com base nessa teoria, aplicou-se a uma turma de $5^{\text {a }}$ série, atual $6^{\circ}$ ano, do ensino fundamental, estratégias de leitura com textos diversos: contos, parábolas e fábulas. Levou-se em conta a importância dessas leituras, ou seja, a relevância do conteúdo na vida do aluno, na comunidade em que ele está inserido, na sua cultura, buscando trabalhar temas que sejam cada vez mais universais.

O estudo aplicado chamou-se intervenção em sala de aula. Com a intenção de inserir os alunos no mundo letrado, tendo como objetivo formar leitores competentes. Nessa intervenção usou-se as estratégias de compreensão leitora para antes, durante e depois da leitura, e confirmou-se a realização de produções escritas, trocas de experiências em relação aos textos trabalhados e a emissão de conclusões e opiniões para uma avaliação crítica.

O artigo Desenvolvimento da compreensão leitora: por um ensino estratégico e efetivo da leitura de Rosângela Maria Couto e Paulo Leandro Carvalho apresenta a leitura como uma prática individual. Essa prática, segundo os autores, deve ser trabalhada com a inserção de procedimentos que garantam a compreensão plena da leitura, em vez de ser apenas uma simples decodificação de palavras. A importância de se tornar um leitor autônomo se faz necessária à medida que todas as áreas do conhecimento utilizam a leitura para sua compreensão, possibilitando ao indivíduo uma vida social e profissional mais participativa. Os autores chamam a atenção para a urgente mobilização de se trabalhar as habilidades leitoras nas escolas, lugar onde a deficiência dessas habilidades mostra-se alarmante. 
Há, no artigo, citações sobre avaliações que revelam as habilidades de estudantes brasileiros em relação à leitura. A primeira avaliação é a Prova Brasil/Sistema de Avaliação da Educação Básica (SAEB), indicando resultados baixos de acordo com a proficiência em leitura dos alunos brasileiros. A segunda avaliação, Programa Internacional de Avaliação de Estudantes (PISA), também indica que esses alunos têm muita dificuldade em leitura, e isso por causa da distorção idade/ano de escolaridade. Logo, há urgência em se trabalhar em sala de aula, de maneira mais efetiva, o ensino da leitura, e é papel do professor orientar todas as estratégias que envolvem a compreensão autônoma da leitura.

A pesquisa apresentada neste artigo é referente aos alunos com idade entre 13 e 16 anos do ensino fundamental de uma escola de Minas Gerais. Eles fazem parte do projeto "Acelerar para Vencer" (PAV). Pela iniciativa da Secretaria de estado da Educação de Minas Gerais e parceria das Secretarias de Educação dos Municípios, caracterizou-se esse projeto como Aceleração da Aprendizagem, focando em uma metodologia que busca sanar as falhas na aprendizagem e melhorar o desempenho dos alunos.

Os pesquisadores aplicaram um questionário, fizeram observações em sala de aula e realizaram oficinas de leitura. Os professores de Língua Portuguesa responderam ao questionário para divulgar com que frequência a leitura era realizada.

Antes de apresentar os dados coletados sobre a pesquisa, os autores discorreram sobre a teoria que envolve a prática da leitura. O domínio da leitura é o que possibilita o desenvolvimento intelectual, desenvolvendo o letramento necessário na vida escolar e social. Auxiliar os alunos a desenvolverem tais habilidades de leitura, como identificar a informação central, observar as partes secundárias do texto, trabalhar significados e perceber intenções e finalidades do texto, é responsabilidade do professor.

Os autores citam também a tecnologia facilitando a comunicação com o uso de imagens e da linguagem oral, sendo para muitos um agravante no incentivo à leitura nos países subdesenvolvidos. Nos países desenvolvidos, essa tecnologia de ponta e repleta de novidades e inovação aparece como um incremento à leitura, enquanto a leitura naqueles países entra em crise principalmente nas escolas, desfavorecendo a realização do trabalho escolar. Sobre a concepção de leitura, os autores citam os Parâmetros Curriculares Nacionais de Língua Portuguesa (1998), fortalecendo essa ideia com as concepções que Solé (1998) traz sobre as estratégias de leitura que permitem uma leitura fluente. Ler não é somente um processo de decodificação, mas de antecipação, verificação e interação.
Sobre o questionário aplicado, as observações feitas em sala de aula e a realização das oficinas de leitura acerca do projeto "Acelerar para vencer", os pesquisadores coletaram os seguintes dados: à leitura continua sendo dado espaço, mas a forma como a prática é realizada em sala de aula não instiga os alunos a desenvolverem estratégias que proporcionem melhor aproveitamento da leitura. Há ainda a leitura em voz alta, atividades que exigem respostas já prontas desfavorecendo a motivação. Mesmo havendo resistência, e alguns alunos não se comportaram bem diante das propostas sugeridas, após a realização das oficinas, constatou-se que é possível ajudar os estudantes, orientando-os como utilizar as estratégias de leitura.

$\mathrm{O}$ artigo Estratégias de leitura e gêneros textuais na formação do leitor crítico de Eliane de Fátima Manenti Rangel, aborda os aspectos linguísticos, cognitivos e sociais da linguagem como uma tarefa complexa. A autora cita as três concepções de linguagem segundo Travaglia (2002): "linguagem como expressão de pensamento, linguagem como instrumento de comunicação e linguagem como processo de interação", destacando a terceira concepção. Rangel (2007) enfatiza que o processo de interação com a linguagem promove um ensino mais produtivo da língua promovendo também o desenvolvimento de habilidades linguísticas para que o aluno tenha a oportunidade de usar a língua de maneira mais eficiente. Com diferentes atividades, propostas pelo professor, sempre visando a interação comunicativa para discutir a própria língua e compreender seu funcionamento, o objetivo de se desenvolver a competência linguística pode ser alcançado. Trabalhar as estratégias de leitura é também uma maneira de se desenvolver o ensino produtivo da língua. A autora também defende esse trabalho relacionando os diferentes gêneros textuais capazes de fornecerem informações diversas acerca da condição e realidade do aluno.

Kleiman apud Rangel (1989), menciona o conhecimento linguístico, referente às palavras e às frases, o conhecimento textual, referente à estrutura de texto apresentado, ou seja, os diferentes gêneros textuais, e o conhecimento de mundo, referente à experiência leitora e à compreensão que se adquire ao avançar naquela leitura.

Percebe-se uma deficiência, por parte das escolas, na utilização das estratégias de leitura. Muitas são as causas para o não desenvolvimento da prática leitora nas escolas, causas essas que a autora não comenta por não ser o objetivo do artigo. A ênfase está em como se trabalhar a leitura, proporcionando motivação, interesse, objetivo, e cabe à escola e ao professor oferecer esse trabalho direcionado para desenvolver cidadãos letrados, 
capazes de dominar sua leitura. O professor é o mediador ou facilitador, aquele que conduz o exercício da leitura acompanhando passo a passo todo o processo que envolve essa prática. Por exemplo, cabe ao professor mostrar o objetivo da leitura, a relação que se pode fazer com texto a ser lido, os elementos relevantes e não relevantes no texto trabalhado e as expectativas que se pode criar em relação ao que foi desvendado: o texto. Acreditase que dessa forma as estratégias são praticadas sem que imposições externas afetem a leitura dos alunos, interessando apenas que eles desenvolvam o hábito da leitura tornando-se autônomos.

Solé apud Rangel (2007), aponta variações que podem ocorrer ao se empregar as estratégias de leitura. Dependendo do objetivo, lê-se porque se quer obter uma informação precisa ou geral, porque se quer verificar a compreensão, porque se quer incentivar e instigar os alunos etc. E o uso de estratégias deve servir para fazer com que o aluno, o leitor, raciocine, desenvolvendo-se intelectualmente. As atividades feitas antes da leitura colaboram para o descobrimento, proporcionando recursos que facilitem a leitura e transforme quem lê em leitor crítico. Falar de gêneros textuais é fundamental para se trabalhar as estratégias de leitura, pois é o texto que organiza a linguagem em diferentes tipologias, podendo ter tamanhos diferentes, conteúdos diversificados e linguagem específica. Como são os humanos que produzem os textos, é pertinente falar que a criação de diferentes textos surgiu com a necessidade de mostrar novos modelos textuais de acordo com a evolução da sociedade.

Contudo, é possível afirmar que por causa das constantes mudanças, assim como a língua evolui, os textos também apresentam evolução, ou seja, pelo seu aspecto histórico, apresentam diferenças na produção, dificultando, muitas vezes, o critério que se usa para definir um gênero textual.

Citando Bronckart (1997), Rangel (2015) diz que há diferenças de gêneros e não se pode considerar que um texto pertença a um tipo textual único porque traz consigo variações linguísticas podendo ser narrativo, descritivo, argumentativo ou explicativo, sendo um deles predominante.

Rangel (2007) cita, por fim, Marcuschi (2003) que afirma que os gêneros textuais atendem a um propósito seja pela sua função, intenção ou interesse. É pertinente mencionar que a diversidade de gêneros é imensa devido à necessidade de se expressar na esfera social, e isso oportuniza o surgimento de outros gêneros. Há, então, a urgência de se trabalhar os gêneros textuais na escola, pois eles trazem uma linguagem dinâmica que constantemente sofre alterações. Prova disso são os e-mails, já mencionados, e os blogs, por exemplo, que têm um vocabulário mais informal, enquanto revistas e periódicos acadêmicos são considerados gêneros mais complexos por usarem uma linguagem mais formal.

\subsection{Análise dos artigos}

Este trabalho tem como principal motivação provar que o estimulo à leitura desenvolve leitores competentes. Um leitor competente é aquele que sabe ler e compreende sua leitura, que identifica elementos implícitos, estabelecendo relações com o que já conhece de outros textos lidos e que atribui ao texto justificativas que validem sua leitura, como menciona Valle em seu artigo A formação do leitor competente: estratégias de leitura.

Nos cinco artigos selecionados e resumidos, consegue-se dados que legitimam a aplicação de estratégias de leitura para uma prática leitora eficiente. Enfatiza-se que não são técnicas precisas para se compreender um texto, como Solé menciona em seu artigo Estratégias de leitura, mas de uma habilidade que se desenvolverá à medida que o hábito pela leitura aumentar, tornando o leitor um leitor autônomo ao planejar a tarefa de ler. As estratégias postas em práticas direcionam a leitura com perguntas sobre o tipo de texto que se tem em mãos? Por que ler esse texto? Qual o conhecimento prévio do assunto que o leitor possui? Para que serve esse assunto/ texto? Qual o objetivo desse texto? Feitas essas perguntas, deixa-se claro o que se pretende com essa leitura. É um procedimento que auxilia o aluno leitor a trabalhar, focando no objetivo da atividade em sala de aula. Tais perguntas também devem ser feitas por um leitor autônomo, pois esse leitor sabe que ler é um constante aprendizado, ler é possuir informações, ler é uma atividade prazerosa e ler é partilhar, fazendo parte do objetivo de leitura de cada um. Se cada leitor conhece suas dificuldades e limitações, com as estratégias de leitura é capaz de solucionar barreiras para uma melhor compreensão como enfatiza Solé (2014).

Para os alunos leitores que estão iniciando sua habilidade de compreensão, trabalhar a leitura usando estratégias de leitura, os fazem aprender a selecionar, criticar e opinar, o que o exercício de leituras feitas simplesmente para encontrar respostas prontas, sem gerar uma informação relevante, não proporciona. É preciso evitar o uso da decodificação pela decodificação no trabalho com a leitura porque os alunos não atribuem sentido ao que leem e não aprendem com essa leitura superficial que fazem, de acordo com Couto e Carvalho no artigo Desenvolvimento da compreensão leitora: por um ensino estratégico e efetivo da leitura. Couto e Carvalho [2007?] ainda expõem que na compreensão leitora há alguns fatores que motivam essa 
compreensão, guiando a leitura conforme a necessidade e o objetivo que ela representa para cada leitor. Entender o que se pretende com tal leitura, principalmente no contexto escolar, permite a aplicação de recursos que favoreçam um trabalho mais envolvente com a leitura, desde que haja motivação. Deste modo, então, o entendimento, a compreensão e o interesse fluirão. Os cinco artigos aqui apresentados assentem em relação à aplicação das estratégias de leitura para uma melhor compreensão do que se lê. Nos cinco artigos também há o consentimento de que o professor é considerado o mediador, responsável por apresentar as estratégias para os alunos e acompanhá-los no processo evolutivo da prática leitora. Rangel ainda assegura em seu artigo Estratégias de leitura e gêneros textuais na formação do leitor crítico que oferecer aos alunos a vivência de diferentes tipos de textos, gêneros textuais e outros estilos de textos, é acrescentar um ensino produtivo da língua.

Sabendo-se que muitos alunos têm dificuldade ao demonstrar sua capacidade de compreensão sobre qualquer leitura, como foi reforçado neste trabalho, esquemas, estratégias, dicas de leitura podem ser desenvolvidas para ensinar a ler proporcionando uma leitura mais produtiva.

\section{CONCLUSÃO}

Dizer que quem lê cresce intelectualmente é afirmar que a leitura é uma prática que desenvolve a mente. Lê-se para se informar e para aprender. Dois objetivos de leitura apresentados nesta pesquisa.

Quando o leitor quer informação, ele procura um tipo de leitura que satisfaça sua necessidade de "estocar" o que deseja. Quando a leitura é direcionada para a aprendizagem, a leitura selecionada não trará apenas informação, mas conhecimento sobre determinado assunto.

Ler é aprender, e se pode aprender a ler e ensinar a ler. Para que isso aconteça é necessário motivação para se aprender e para se ensinar. A capacidade que o ser humano tem de se comunicar usando diferentes recursos e linguagem para atingir um objetivo pode ser estendido à capacidade $\mathrm{e}$ habilidade leitora. Lê-se a todo instante, pois todos estão expostos ao bombardeio de informação diária. Saber selecionar o que se lê é uma estratégia que pode ser aprendida.

Sem dúvida o professor é o responsável em estreitar a relação leitor e leitura orientando seus alunos a desempenharem as estratégias de leitura. Mostrando como elas funcionam e deixando claro que, como leitores, podemos, cada um, elaborar uma estratégia que melhor se ajuste à leitura auxilia o aluno leitor a ter cada vez mais habilidade e gosto pela leitura. Gosto esse que se torna um hábito, e que com a prática forma leitores críticos e pensantes.

A tecnologia também divulga a informação, beneficiando a aprendizagem. É pertinente citar que a evolução tecnológica contribuiu para o surgimento de novos estilos de textos. Como já foi mencionado, o email é um tipo de gênero textual que veio suprir a necessidade de se usar essa comunicação de maneira mais dinâmica. Pode-se dizer, então, que com tanta diversidade de leitura, classificar os tipos de textos conforme seu gênero textual é algo essencial para promover uma leitura cada vez mais exigente. Mesmo havendo certas desconformidades quanto à classificação de diferentes tipos de texto, muitas vezes, não sendo clara a classificação de seu gênero, é essencial trabalhar gêneros textuais enfatizando a predominância de um estilo em relação a outro.

Entende-se, então, que ensinar a ler e aprender a ler é possível, desde que haja motivação para a realização dessa prática. A motivação deve vir de quem ensina e de quem aprende para que a interação e o aprendizado aconteçam. As estratégias de leitura fazem parte dessa motivação, e o mediador, sendo muitas vezes o professor, é o responsável por conduzir que essas estratégias sejam seguidas e praticadas de acordo com o objetivo de cada leitura.

As aulas de Língua Portuguesa precisam assumir a postura de instruir e utilizar amplamente as estratégias de leitura, e a prática pedagógica tem que se comprometer com esse trabalho a ser estendido às demais áreas do conhecimento. Isso significa estabelecer interdisciplinaridade nos projetos pedagógicos, como destaca Lois (2012, p.25), uma vez que a leitura está presente em diversas literaturas. Logo, é responsabilidade do professor educador fazer esta articulação. Já são muitas e variadas as práticas que podem ser aproveitadas para um trabalho mais efetivo com a leitura. Fazê-las acontecerem é papel do mediador de leitura que participará desta etapa na vida do leitor a qual ele, o leitor, entenderá que lendo mais conseguirá ser mais fluente e influente, sabendo posicionar-se e tendo seus próprios pensamento. Proporcionar o prazer da leitura é um compromisso a ser posto em prática, pois o domínio da leitura é fundamental para o desenvolvimento de uma sociedade, de uma nação. Quem compreende e interpreta o que lê é considerado letrado, capaz de enfrentar desafios sempre em busca de novos saberes.

\section{REFERÊNCIAS}

ADLER, Mortimer J.; DOREN, Charles Van. Como

ler livros: o guia clássico para a leitura inteligente. 3 . ed. São Paulo: Realizações, 1972. 
ALCURE, Lenira; FERRAZ, Maria N. S.; CARNEIRO, Rosane. Comunicação verbal e não verbal. Rio de Janeiro: SENAC/DN/DPF, 1996.

BORDINI, Maria da Gloria; AGUIAR, Vera Teixeira de. Literatura: a formação do leitor. Porto Alegre: Mercado Aberto, 1988.

COSCARELLI, Carla Viana. Dicas sobre estratégias de leitura. [2012?]. Disponível em: $<$ https://docs.google.com/viewer?a=v\&pid=sites\&src id=ZGVmYXVsdGRvbWFpbnxyZWRpZ2lydWZtZ 3xneDo0MTMxYmUwOWViOTQ2YTRi> Acesso em: 19 out. 2014.

COUTO, Rosângela Maria; CARVALHO, Paulo Leandro de. Desenvolvimento da compreensão leitora: por um ensino estratégico e efetivo da leitura. [2007?]. Disponível em:

$<$ http://br.librosintinta.in/estrategia-de-leitura-solepdf.html> Acesso em: 19 out. 2014.

KOCH, Ingedore Villaça; ELIAS, Vanda Maria. Ler e compreender: os sentidos do texto. 3. ed. São Paulo: Contexto, 2012.

LOIS, Lena. Teoria e prática da formação do leitor: leitura e literatura na sala de aula. Porto Alegre: Artmed, 2010.
MACHADO, Ana Maria. Como é porque ler os clássicos universais desde cedo. Rio de Janeiro: Objetiva, 2002.

PIMENTEL, Carlos. Redação descomplicada. 2. ed. São Paulo: Saraiva, 2012.

RANGEL, Eliane de Fátima Manenti. Estratégias de leitura e gêneros textuais na formação do leitor crítico. In: CONGRESSO DE LEITURA DO BRASIL, 16., 2007, Campinas. [Anais...], Campinas: Unicamp, 2007. p. 1-10. Disponível em:

$<$ http://alb.com.br/arquivomorto/edicoes_anteriores/a nais16/sem03pdf/sm03ss07_05.pdf > Acesso em: 19 jan. 2015.

SOARES, Angélica. Gêneros literários. 7. ed. São Paulo: Ática, 2007.

SOLÉ, Isabel. Estratégias de leitura. [2000?]. Disponível em:

<http://www.professorefetivo.com.br/resumos/Estrate gias-de-Leitura.html> Acesso em 19 out. 2014.

VALLE, Maria de Jesus Ornelas. A formação do leitor competente: estratégias de leitura. [2007?]. Disponível em:

<http://br.librosintinta.in/estrategia-de-leitura-solepdf.html> Acesso em 19 out. 2014. 